\title{
Binding Relations and Their Implications for Word Order in Arabic
}

\author{
Mamdouh Ayed Alenazy \\ Department of English Language and Literature, Al-Hussein Bin Talal University, Jordan
}

\begin{abstract}
This study aims at investigating the distribution of the possessive pronouns in Modern Standard Arabic. It shows that when the possessive pronouns are used as reflexives they have implications for the word order. The different positions occupied by the objects are determined by the presence of these pronouns and the binding relations within the c-commanding domain. Building on the basic assumptions of Binding Theory, possessive pronouns are best treated as normal pronominal elements which are subject to condition $B$. However, when they are used as anaphoric elements in certain contexts, they have to be c-commanded by their antecedents. Depending on the derivational level at which c-command relation is established between the reflexive possessive pronoun and its antecedent, movement of the possessive pronoun along with the phrase containing is optional in certain structures or, in other structures, the pronoun becomes frozen in the position in which it is base-generated.
\end{abstract}

Index Terms - Arabic, binding theory, C-command, reflexives, possessive pronouns

\section{INTRODUCTION}

It has been observed by a number of authors that possessive pronouns in different languages can be ambiguous between normal pronouns and reflexives. In English, for example, the possessive pronoun can be interpreted as a pronoun or a reflexive as (1a) and (1b) below illustrate respectively (cf. Rooryck \& Vanden Wyngaerd, 2011; Truswell, 2014).

(1) a. The $\operatorname{man}_{\mathrm{i}}$ likes his $\mathrm{s}_{\mathrm{k}}$ house.

b. The man $_{\mathrm{i}}$ likes his $_{\mathrm{i}}$ house.

Being a reflexive, the possessive pronoun is bound locally in (1b), which is not the case in (1a) where the pronoun is free locally. Modern Standard Arabic (henceforth MSA) is similar to English in this respect. As the examples (2a) and (2b) below show, the possessive pronoun can be used as an anaphoric reflexive which is bound or as a normal pronoun that has to be free locally (cf. Benmamoun \& Choueiri, 2013).

(2)
a. zara
ar-rajul $\mathrm{i}_{\mathrm{i}} \mathrm{u}$
visited.3ms the- $\operatorname{man}_{\mathrm{i}}$-nom
'The man visited his friend'
sadeeq-a-hu $\mathrm{i}_{\mathrm{i} / \mathrm{k}}$
friend-acc-his $\mathrm{s}_{\mathrm{i} / \mathrm{k}}$
b. ya?almu ar-rajul $\mathrm{i}_{\mathrm{i}} \mathrm{u}$ an tazura al-mumaridat- $\mathrm{u}$
hope. $3 \mathrm{~ms}$ the- $\mathrm{man}_{\mathrm{i}}$-nom that visit-3fs the-nurse-nom
'The man hopes that the nurse visits his friend.'

In (2a) the possessive pronoun can have a reflexive reading; hence, it is co-indexed with the c-commanding DP subject. In (2b) it is a normal pronoun which has no antecedent within the same domain (i.e. that clause which constitutes a CP). In fact, the anaphoric possessive pronoun which behaves as a reflexive bears resemblance to the true reflexive in both the form and use. Morphologically, the Arabic reflexive is composed of a possessive pronoun and the noun nafs 'self'. Thus, the structure of the true reflexive in (3) below is identical to the combination of the possessive pronoun and the noun in (2a) above.
(3) yuhibu ar-rajul $\mathrm{i}_{\mathrm{i}} \mathrm{u} \quad$ nafs-a-hu $\mathrm{i}_{\mathrm{i} / \mathrm{k}_{\mathrm{k}}}$
like.3ms the-man ${ }_{\mathrm{i}}$-nom $\quad$ self-acc-his $\mathrm{i}_{\mathrm{i} / \mathrm{k}}$
'The man likes himself.'

The similarity between the possessive pronoun which has a reflexive reading in (2a) and the possessive pronoun which is part of the true reflexive in (3) is confirmed by the fact that they both have the same distribution. In other words, what applies to the whole structure of the true reflexive applies to the object which contains the possessive pronoun in (2a) in terms of Case marking and word order. In addition to the VSO word order in (2) and (3) above, VOS word order is possible.
(4)
a. zara
sadeeq-a-hu $/ \mathrm{i} / \mathrm{k}$
visited.3ms friend-acc-his
ar-rajul $\mathrm{i}_{\mathrm{i}} \mathrm{u}$
the-man ${ }_{\mathrm{i}}$-nom
'The man visited his friend'
b. yuhibu nafs-a-hu $\mathrm{i}_{\mathrm{i}}$ *k
like.3ms self-acc-his $\mathrm{i}_{\mathrm{i} / \mathrm{k}}$
ar-rajul $\mathrm{i}_{\mathrm{i}} \mathrm{u}$
the - man $_{\mathrm{i}}$-nom
'The man likes himself.' 
MSA is predominantly VSO language which allows SVO as an alternative word order. However, VOS word order is generally allowed with topicalized objects or when the object is a pronominal clitic attached to the verb; the pronominal object appears in a position preceding the subject (cf. Alenazy, 2009 for extensive discussion). However, VOS word order is obligatory under certain conditions. Binding relations have their implications for the positions occupied by the object; therefore, the word order of the subject and the object must achieve c-command relations (see the discussion below). As (5) below shows, when the anaphoric possessive pronoun, which is coreferential with the object, appears within the structure of the subject, VSO word order is disallowed.
(5) *dahana
sahib-u-hu
al-bayt $\mathrm{i}_{\mathrm{i}}$-a
painted.3ms
owner-nom-its
the-house $\mathrm{i}_{\mathrm{i}}$-acc
'Its owner painted the house.'

This sentence is ruled out because its configurational structure, as we shall see later in section 4 below, does not achieve the required c-command relation between the antecedent (i.e. the object) and the anaphor (i.e. the possessive pronoun within the structure of the subject). Nevertheless, this assumption does not seem to be straightforward as, contra to (5) above, when the anaphoric pronoun is contained within the structure of the object, VOS word order is allowed. In (6) below, the anaphoric coreferential possessive pronoun is in a superficial position preceding the antecedent.
(6)
dahana
bayt-a-hu $u_{i}$
at-tajir $\mathrm{i}_{\mathrm{i}}-\mathrm{u}$
painted. $3 \mathrm{~ms} \quad$ house-acc-his $\mathrm{i}_{\mathrm{i}}$
the-merchant $\mathrm{i}_{\mathrm{i}}$-nom

This paper concerns itself with the contrast between these two word orders and how they are linearly achieved; it explains why the anaphoric pronoun in (6) can precede the antecedent while it cannot in (5). It claims that the object position with respect to the subject is determined by the presence of an anaphoric element within the structure of the object itself or the structure of the subject. Put differently; if the structure of the object contains an anaphoric element that is coreferential with the subject, the object can optionally move to a position preceding the subject, i.e. optional VOS word order. However, if the anaphoric element is within the structure of the subject and it is coreferential with the object, object movement to a position preceding the subject becomes obligatory and the subject is frozen in its canonical position. I ascribe this discrepancy to c-command relations. I argue that if c-command relation between the antecedent (the subject) and the coreferential anaphoric pronoun within the DP object is obtained during the course of derivation while they are in their base positions the object, along with the anaphor within its structure, is allowed to move to a position preceding the subject as in (6) above. However, if c-command relation is obtained during the course of derivation by object movement of the antecedent to a position preceding the subject to bind the anaphoric pronoun within its structure, the subject is frozen in its base position in accordance with what I call Anaphor Freezing Condition (henceforth AFC). The proposed analysis adopts the latest minimalist assumptions made in Chomsky (1995, 2007, 2008). The CP, as a phase, is taken as the minimal c-commanding domain within which constraints about binding relations are established. The notions of External Merge (i.e. the operation Merge) and Internal Merge (i.e. the operation Move) are essential for the description and analysis of the reflexive possessive pronouns and their distribution.

\section{BINDING RELATIONS}

Binding Theory is concerned with the distribution of nominal elements based on structural configurations. The early version of Binding Theory (Chomsky 1981) does not in fact distinguish between binding and coreference. However, many authors have distinguished between the two concepts. For example, Reinhart (1983) argues that binding condition are concerned with syntactic binding not coreference. Binding Theory defines a c-commanding domain within which the use of different nominal elements is determined by different conditions (Reinhart 1976; Chomsky 1981). The ccommanding domain, according to Chomsky (1995), is the minimal clause structure within which both the antecedent and the anaphor exist. In line with Chomsky (2008), clause structure is represented as a CP. Nominals are classified into the following three different types:

i. Anaphors, such as reflexives, which derive their meanings from nouns preceding them within the same ccommanding domain.

ii. Pronouns which derive their meanings from nouns outside the c-commanding domain.

iii. R-expressions which derive their meanings from the entities to which they refer in the real world.

While an anaphor is bound locally in that it is c-commanded by a co-indexed antecedent that exists in the same domain, a pronoun can be co-indexed with a noun that should not be in a c-commanding position; i.e. it is free locally. R-expressions are always free. The constraints on the distribution of these nominal elements, which are known as Binding Conditions (cf. Chomsky 1981), are:

Condition A: anaphors are bound locally.

Condition B: pronouns are free locally.

Condition C: R-expression are free everywhere.

Conventionally, since Reinhart (1976), when the antecedent binds a coreferential pronoun, the former has to asymmetrically c-command the latter. The structure (7) below shows the configurational relationship between the 
antecedent $\mathrm{A}$ and the coreferential pronoun $\mathrm{B}$. The c-command relation here is said to be asymmetrical because $\mathrm{A} \mathrm{c}-$ commands $\mathrm{B}$ but $\mathrm{B}$ does not c-command $\mathrm{A}$.

(7)

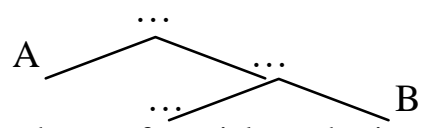

In MSA, the coreferential anaphoric pronoun normally follows its antecedent as we can see from (8) below.
(8) dahana at-tajir $\mathrm{r}_{\mathrm{i}} \mathrm{u} \quad$ bayt-a-hu $\mathrm{u}_{\mathrm{i}}$
painted.3ms the-merchant $\mathrm{i}_{\mathrm{i}}$-nom house-acc-his $\mathrm{s}_{\mathrm{i}}$

'The merchant painted his house.'

In this sentence, the object contains a reflexive possessive pronoun which is coreferential with the subject. The grammaticality of the sentence suggests that the reflexive possessive pronoun is c-commanded by the subject, as the structure (9) shows.

(9)

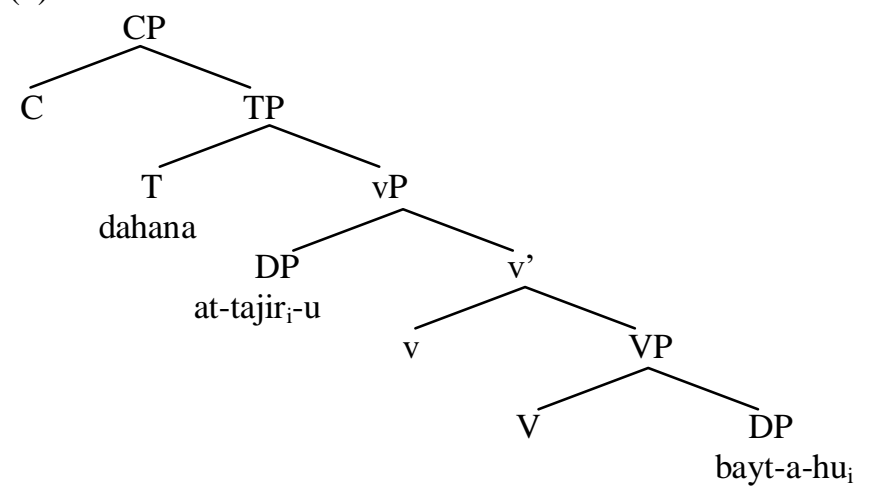

The ungrammaticality of the following sentence demonstrates that the c-command relation is crucial. The coreferential possessive pronoun here is contained within the structure of the subject and it has the object as its antecedent, which is not in a c-commanding position. The sentence in (5) above is repeated here as (10).
(10) *dahana
painted.3ms
$\underline{\text { sahib-u-hu }}$
al-bayt $\mathrm{i}_{\mathrm{i}}$ -
'Its owner painted the house.'
the-house $\mathrm{i}_{\mathrm{i}}$-acc

The structure (11) below illustrates that the object does not c-command the anaphoric pronoun, which means that the former cannot bind the latter.

(11)

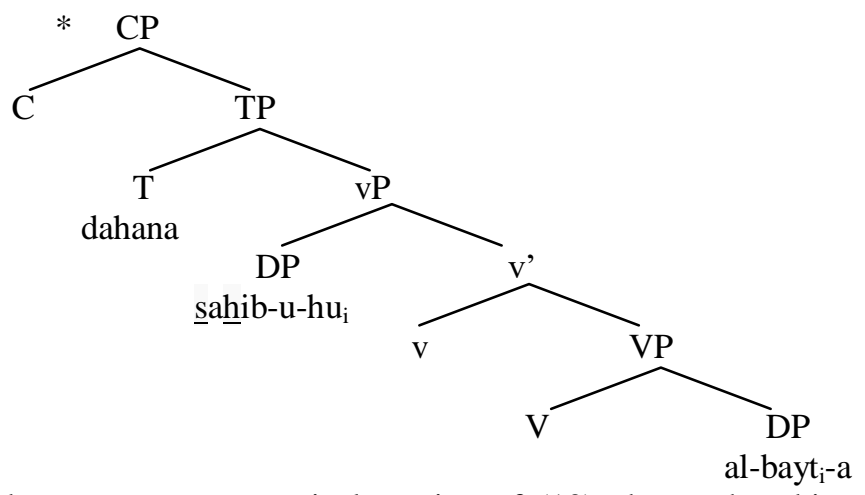

In order to get a grammatical version of (10) above, the object is obligatorily moved to a position intervening between the verb in T and the subject in the specifier of vP. I assume following Alenazy (2009) that this position is an outer specifier of vP. From this position the object binds the possessive anaphoric pronoun; hence, the following sentence is grammatical.
(12) dahana
al-bayt $\mathrm{t}_{\mathrm{i}} \mathrm{a}$
sahib-u-hu
painted.3ms the-house $\mathrm{i}_{\mathrm{i}}$-acc
owner-nom-its
'The house's owner painted it.'

Interestingly, however, the object with the coreferential possessive pronoun in (8) can be moved to a position preceding the subject. In contrast with (12), where object movement is obligatory, object movement is optional in (6) above which is repeated here as (13).
(13) dahana bayt-a-hu $\mathrm{i}_{\mathrm{i}}$ at-tajir $\mathrm{r}_{\mathrm{i}} \mathrm{u}$
painted.3ms house-acc-hisi the-merchanti-nom

'The merchant painted his house.'

Apparently, (8) and (12) raise no problems because the antecedents linearly precede the coreferential reflexive possessive pronouns. However, the question arises here is: why is the contrast between (10) and (13)? 
The contrast between (10) and (13) is explained in the Arab grammarians' literature (cf. Hassan, 1961; Ibn Hisham, 1964, for instance) in terms of grammatical-function hierarchy which claims that the rank of the subject is hierarchically higher than the rank of the object. ${ }^{1}$ In (10), the coreferential pronoun which is contained within the subject cannot refer to the unmoved object because the rank of the latter is lower than that of the subject. Consequently, the object has to linearly precede the reflexive pronoun, as (12) above shows.

In (8), on the other hand, linear precedence is not necessary, which means that object movement is optional, as in (13). This optionality is ascribed to the fact that the rank of the antecedent, i.e. the subject, is higher than the rank of the object which contains the coreferential pronoun (cf. Mohammad, 2000). However, the ungrammaticality of the following sentence is not captured by the Arab grammarians' explanation.

(14) *ra?at ibnat-a-hu $\mathrm{i}_{\mathrm{i}}$ Pum-u ar-rajul $\mathrm{i}_{\mathrm{i}} \mathrm{i}$ saw.3fs daughter-acc-his $s_{i}$ mother-nom the- $\operatorname{man}_{i}$-gen

'The man's mother saw his daughter.'

Under the assumptions of the Arab grammarians, (14) should be grammatical as it is can be treated on a par with (13). However, the coreferential possessive pronoun within the structure of the object ibnat-a-hu 'his daughter' cannot precede its antecedent $\operatorname{ar}_{-}$rajul $_{i}-i$ 'the man' which is contained within the structure of the subject that has a higher rank than the pronominal object. In other words, VOS word order is not allowed here; it is possible only if the possessive pronoun is free and in this case it is subject to condition B. With the reflexive reading of the possessive pronoun the antecedent must precede, hence the grammaticality of (15) below.
(15) rapat
?um-u ar-rajul $\mathrm{i}_{\mathrm{i}} \mathrm{i}$
ibnat-a-hu saw.3fs mother-nom the- $\operatorname{man}_{i}$-gen
daughter-acc-his ${ }_{i}$
'The man's mother saw his daughter.'

I shall argue below for a different explanation that can capture both (14) and (15) and at the same time accounts for why object movement is obligatory and optional in (12) and (13) above respectively. I attribute the grammaticality and ungrammaticality of these sentences to the presence of different types of c-command relations.

\section{CoReferential PRonouns AND C-COMMAND Relations}

The data show that the coreferential pronoun, and the DP within which it is contained, must remain in its base position if it is not c-commanded by its antecedent when they are externally merged before any Move operation takes place. The c-command relation that is achieved by movement (i.e. Internal Merge) of the antecedent to a position preceding the coreferential reflexive pronoun is not enough to allow the latter to move. I refer to this restriction on the movement of the coreferential reflexive possessive pronoun as AFC and initially reformulate it as follows:

(16) A reflexive possessive pronoun along with the DP within which it is exists is frozen in its base position if it is not c-commanded by its antecedent at the stage of External Merge.

It is worth mentioning at this juncture that Binding itself does not derive movement. Rather, movement of the antecedent of a reflexive is triggered by its need to be highlighted or focused. In fact, the idea of this interaction between Binding and focus is not new as it has been investigated by several authors in different languages (cf. Baker, 1995; Charnavel, 2009). I assume that focus is the underlying force of the antecedent movement required by the condition (16). Furthermore, AFC I am assuming here is different from Freezing Effect, a well-known condition on operator-variable relations. According to Bošković (2008), "[o]perators in operator-variable chains cannot undergo further operator movement." (p. 250). To exemplify, in (17b) below, the noun phrase every problem is topicalised (by movement) establishing an operator-variable relation. Both sentences below are taken from Bošković (2008).

(17) a. Someone thinks that Mary solved every problem.

b. Someone thinks that every problem, Mary solved.

Bošković argues that the topicalization has freezing effect. The topicalized noun phrase in (17b) cannot undergo quantifier raising because it is located in an operator position before quantifier raising takes place. Rizzi (2006) deals with freezing effect in terms of the criterial properties of the position occupied by the moved item. In a clause such as which book should you read?, Rizzi (2006) claims that the wh- phrase which book has two interpretive properties. The first is that it is a patient of the verb read; the second property is that it is an interrogative operator. While the first property is of a semantic nature, the second property is criterial. Criterial position is determined by "Criteria" which require that a specifier-head configuration between a given head and question words, Topics and Foci. Rizzi's Criterial Freezing claims that a "phrase meeting a criterion is frozen in place" (Rizzi, 2006, p.112) [Emphasis added]. The following examples illustrate that the wh- phrase cannot undergo further movement in (18b) because it has met the criterial properties of the specifier position of $\mathrm{CP}$ in the embedded clause.

(18) a. Bill wonders [which book $\mathrm{C}$ [she read t]]

b. *Which book $\mathrm{C}$ does Bill wonder [t $\mathrm{C}[$ she read $\mathrm{t}]]$ ?

\footnotetext{
${ }^{1}$ Arab grammarians' grammatical - function hierarchy is similar to the relational hierarchy (cf. Johnson, 1977) which claims that the subject outranks the direct object and the direct object outranks the indirect object.
} 
In this paper, I restrict the use of the term freeze to the DP which contains a reflexive possessive pronoun. Depending on the configurational structure and the relative position of this DP with respect to other constituents within the ccommanding domain, its movement is sometimes not allowed; i.e. it is frozen in its base position.

Let us now see how the condition (16) is satisfied in (13) but not in (10) and (14) above. (10) is ungrammatical because the coreferential pronoun within the subject is not c-commanded by the object antecedent. Therefore, the object is required to move to a position preceding the subject in order to c-command the coreferential pronoun, as in (12) above. Since the c-command relation between the antecedent (the object) and the coreferential pronoun is achieved by movement of the former, we find that, in conformity with (16) above, the movement of the subject to a preverbal position is completely disallowed.
(19) * sahib-u-hu $_{\mathrm{i}}$ dahana owner-nom-it $\mathrm{i}_{\mathrm{i}}$ painted.3MS
'Its owner painted the house.'
al-bayt $\mathrm{i}_{\mathrm{i}} \mathrm{a}$
the-house $\mathrm{i}_{\mathrm{i}}$-acc

Put differently, subject movement to a preverbal position induces a violation of the AFC condition. One might ask then why the object movement which contains the coreferential pronoun in (13) does not violate this condition. The answer to this question is straightforward. The base position of the subject is higher than that of the object (see the structure (9) above). The c-command relation between the coreferential pronoun within the object and its antecedent (the subject) is established while both elements are in their base positions. Therefore, the condition (16) allows the movement of the object across the subject. In fact, the object can move not only to a position preceding the subject but also to a preverbal position. In a sharp contrast with (19), the movement of the object with the coreferential pronoun to a preverbal position is acceptable as the grammaticality of (20) below suggests.
(20) bayt-a-hu dahana at-taji $\mathrm{r}_{\mathrm{i}}-\mathrm{u}$ house-acc-his $\mathrm{i}_{\mathrm{i}}$ painted.3ms the-merchant $\mathrm{i}_{\mathrm{i}}$-nom
'The merchant painted his house.'

Building on this discussion, we return now to account for the ungrammaticality of (14) above, repeated below as (21) for convenience. In this sentence, the object which has the coreferential reflexive pronoun appears in a position preceding the subject which has the antecedent within its the structure. In contrast with (13) above, this object movement here renders the sentence ungrammatical.
(21) *ra?at ibnat-a-hu $\mathrm{i}_{\mathrm{i}}$ Pum-u saw.3fs daughter-acc-his s $_{\mathrm{i}}$ mother-nom
'The man's mother saw his daughter.'

$$
\text { the-man }{ }_{\mathrm{i}} \text {-gen }
$$$$
\text { ar-rajul } i_{i}-\mathrm{i}
$$

One possible scenario to account for the difference between (21) and (13) above and why the movement of the object with the anaphoric pronoun is possible in (13) while it is not in (21) is to assume that in the VSO variant of (21) the antecedent ar-rajul which is contained with the DP structure of the subject can by no means c-command the reflexive possessive pronoun as the structure (22) below illustrates:

(22)

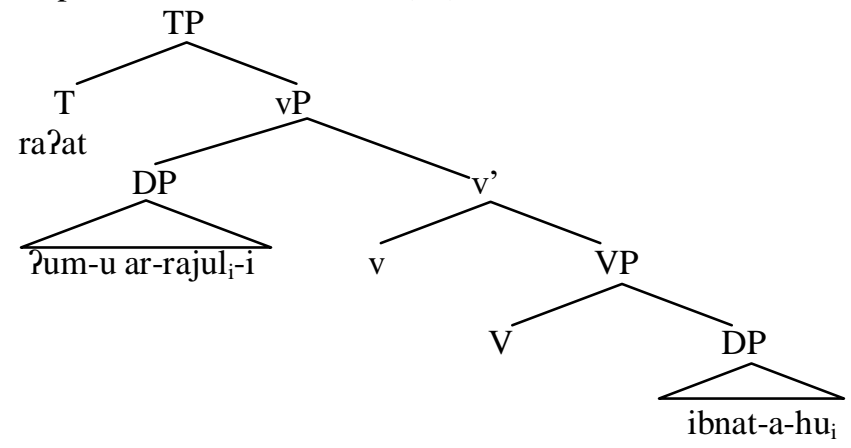

This means, in other words, that the possessive pronoun is not anaphoric, and it is free in this context. However, this conclusion cannot be taken for granted. If the possessive pronoun were free, its appearance before or after the subject (i.e. VSO or VOS word orders) would raise no problems. The possessive pronoun cannot refer to the noun ar-rajul- $u$ if it follows it; the sentence is acceptable only if the DP object which contains the possessive pronoun remains in situ, as in (15) above, repeated here as (23), which suggests that the possessive pronoun is bound locally and this implies that a type of c-command relation is present.
saw.3fs mother-nom the-man ${ }_{i}$-gen
'The man's mother saw his daughter.'
(23) ra?at Pum-u ar-rajul $\mathrm{i}_{\mathrm{i}} \mathrm{i}$

$$
\begin{aligned}
& \text { ibnat-a-hu }_{\mathrm{i}} \\
& \text { daughter-acc-his } \\
& \text { in }_{i}
\end{aligned}
$$

In fact, the sentence (23) is problematic and its behaviour casts doubts on the validity of the condition (16) above. On the one hand, its grammaticality suggests that there must be a kind of c-command relation that allows the anaphoric reading of the coreferential possessive pronoun contained within the structure of the object. On the other hand, it seems to obey the condition (16) above; the movement of the unc-commanded anaphoric reflexive renders the sentence ungrammatical. Accordingly, the current version of AFC, as represented in (16) above, doesn't capture (21). To propose 
a unified analysis that account for all the instances of the anaphoric possessive pronouns discussed so far, I revisit the condition (16) above in the following section.

\section{TOWARDS AN ANALYSIS}

I argue that an explanation for how the coreference relation is established between the antecedent and the reflexive possessive pronoun in (23) above is obtained by adopting the notion of indirect binding (cf. Kayne, 1994; Hornstein, 1995; Boeckx, 2003). According to Hornstein (1995), binding of a coreferential pronoun by a non-c-commanding antecedent is possible under what he calls the notion of "almost c-command" (p. 108). He proposes that the specifier position of a given DP can acquire the c-command domain of the whole DP; in other words, he argues that a pronoun can be bound by its antecedent if this antecedent c-commands the pronoun or when the maximal projection that dominates the antecedent c-commands the pronoun.

I extend Hornstein's (1995) notion of almost c-command, and call it indirect c-command, to our present analysis and propose that in (23) the antecedent can bind the coreferential pronoun because the maximal projection that contains the antecedent, i.e. the whole DP, c-commands the possessive pronoun within the structure of the object. In other words, the coreferential pronoun is c-commanded indirectly by the antecedent.

However, this kind of indirect c-command has to be distinguished from the normal c-command, which I will refer to here as direct c-command. ${ }^{2}$ In the light of this distinction, I revise the condition (16) above as follows:

(24) A reflexive possessive pronoun along with the DP within which it exists is frozen in its base position if it is not directly c-commanded by its antecedent at the stage of External Merge.

The revised version of AFC in (24) above captures all the examples discussed so far. It implies, on the one hand, that a DP which contains a reflexive pronoun can move from its base position if the direct c-command relation between the antecedent and the reflexive possessive pronoun is achieved when they are first merged. On the other hand, indirect ccommand (i.e. almost c-command, using Hornstein's term) suffices to allow coreference and binding between the reflexive possessive pronoun within the structure of the object and its antecedent within the structure of the subject, but it does not allow object movement. It explains perfectly why the object movement is obligatory in (12) and optional in (13) above. In (12), as discussed earlier in the previous section, object movement is obligatory to bind the coreferential reflexive possessive pronoun within the structure of the subject. Because this c-command relation is achieved by Internal Merge (i.e. object movement) the subject becomes frozen; in conformity with the AFC, its movement to a preverbal position is not possible; accordingly, (19) above is ungrammatical. However, in (13) the reflexive possessive pronoun within the object is c-commanded by its antecedent at the stage of External Merge. Therefore, the object is not frozen and it can optionally move to a position preceding the subject. The condition also captures (23) above. The object cannot move because, in accordance with what the condition requires, the reflexive possessive pronoun is not ccommanded directly by its antecedent. As a result, it cannot move. Building on the behavior of the examples above and on the presented discussion, we conclude that different MSA word orders achieved by object movement are restricted. When reflexive possessive pronouns are present, the movement of the DP phrase containing them, be it the subject or the object, is attributed to two constrains. The first is AFC (24) above, and the second is related to whether the ccommand relation is achieved at the stage of the External Merge or the stage of the Internal Merge.

\section{SUMMARY AND CONCLUSION}

To summarize the discussion and conclude, object movement across the subject is optional, in principle. However, depending on the binding (and c-command) relations and on whether the reflexives are contained within the DP structure of the subject or the object, object movement becomes obligatory or disallowed. Object movement to a position that linearly precedes the subject is obligatory when the subject structure contains a reflexive possessive pronoun that is coreferential with the object. However, in contexts where the antecedent within the structure of subject does not directly c-command the anaphoric possessive pronoun within the structure of the object, object movement is disallowed, which is not the case when direct c-command is achieved; the object with the possessive reflexive pronoun moves optionally to a position preceding the subject antecedent. These different possibilities of object movement which is strongly associated with the presence of reflexive possessive pronouns within the c-commanding domain result in different word orders. I argued that the movement of a DP containing a reflexive pronoun is subject to AFC that

\footnotetext{
${ }^{2}$ My definition of indirect c-command in this paper departs from Zubizarreta's (1998) definition. She distinguishes between direct c-command and indirect c-command; the former corresponds to the standard definition of c-command. However, the latter holds between a specifier and its sister. In the structure (i) below, the ZP in the specifier position directly c-commands both the head $\mathrm{X}$ and the complement $\mathrm{YP}$, and indirectly c-commands its sister $\mathrm{X}^{\prime}$ because it is the projection of the directly c-commanded items.

i)

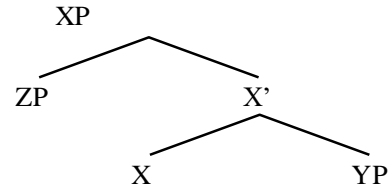


requires an established direct c-command relation at the stage of External Merge; if this requirement is not met, movement is not permitted and the DP containing the reflexive is frozen in its base position.

\section{REFERENCES}

[1] Alenazy, M. (2009). Case, agreement and movement in Arabic: a Minimalist approach. Saarbrücken, Germany: VDM Verlag Publishing Company.

[2] Baker, C. L. (1995). Contrast, discourse prominence, and intensification, with special reference to locally-free reflexives in British English. Language, 71 (1): 63-101.

[3] Benmamoun, E. \& L. Choueiri. (2013). The syntax of Arabic from a generative perspective. In J. Owens (ed.), The Oxford handbook of Arabic linguistics. Chicago: Oxford University Press, 115-164.

[4] Boeckx, C. (2003). (In)Direct binding. Syntax 6: 213-36.

[5] Bošković, Ž. (2008). On the operator freezing effect. Natural Language \& Linguistic Theory 26: 249-87.

[6] Charnavel, I. (2009). Linking Binding and Focus: on Intensifying son propre in French. Unpublished MA Thesis. University of California, Los Angeles.

[7] Chomsky, N. (1981). Lectures on Government and Binding. Dordrecht, Holland; Cinnaminson, N.J.: Foris Publications.

[8] Chomsky, N. (1995). The Minimalist Program. Cambridge, Mass: MIT Press.

[9] Chomsky, N. (2001). Derivation by phase. In Kenstowicz, M. (ed.), Ken Hale. A Life in Language. Cambridge, Mass: MIT Press, 1-52.

[10] Chomsky, N. (2007). Approaching UG from below. In U. Sauerland \& H.-M. Gärtner (eds.), Interfaces + Recursion = Language?. Berlin: De Gruyter, 1-30.

[11] Chomsky, N. (2008). On phases. In R. Freidin, C. P. Otero, \& M. L. Zubizarreta (eds.), Foundational Issues in Linguistics Theory. Cambridge, MA: MIT Press, 133-166.

[12] Hassan, A. (1961). an-nahw al-wafi. Cairo: dar al-ma'araef.

[13] Hornstein, N. (1995). Logical Form: From GB to Minimalism. Oxford: Blackwell.

[14] Ibn Hisham, J. (13th century). Mughni al-labeeb. Damascus: Darul feker (1964).

[15] Johnson, D. E. (1977). On relational constraints on grammars. In Cole, P. \& J. M. Sadock (eds.), Syntax and Semantics 8: Grammatical Relation. New York: Academic Press, 151-78.

[16] Kayne, R. S. (1994). The antisymmetry of Syntax. Cambridge, Mass: MIT Press.

[17] Mohammad, A. M. (2000). Word order, agreement, and pronominalization in Standard and Palestinian Arabic. Amsterdam: Benjamins.

[18] Reinhart, T. (1976). The syntactic domain of anaphora. Doctoral Dissertation. MIT.

[19] Reinhart, T. (1983). Anaphora and semantic interpretation, Croom-Helm, London.

[20] Rizzi, L. (2006). On the form of chains: Criterial positions and ECP effects. In Cheng, L. L.-S. \& N. Corver (eds.), Whmovement: Moving on. Cambridge MIT Press, 97-133.

[21] Rooryck, J. \& G. Vanden Wyngaerd. (2011). Dissolving Binding Theory. Oxford: Oxford University Press.

[22] Truswell, R. (2014). Binding theory. In Carnie, Andrew, Yosuke Sato, and Daniel Siddiqi (eds.), Routledge Handbook of Syntax. Abingdon. Taylor \& Francis, 214-238.

[23] Zubizarreta, M. L. (1998). Prosody, focus, and word order. Cambridge, Mass: MIT Press.

Mamdouh Ayed Alenazy is an associate professor of linguistics in the Department of English Language and Literature at AlHussein Bin Talal University, Jordan. He received his BA in English Language and Literature in 2001 from Al-Hussein Bin Talal University, his MA in Syntax from Essex University in 2004, and his PhD in linguistics from Newcastle University in 2009. His major research interests include syntactic theory with emphasis on the Minimalist Program, syntax-semantics interfaces and their implications for translation. 